\title{
Home delivery among antenatal care booked women in their last pregnancy and associated factors: community-based cross sectional study in Debremarkos town, North West Ethiopia, January 2016
}

\author{
Habtamu Kebebe Kasaye ${ }^{1 *}$, Zerfu Mulaw Endale ${ }^{2}$, Temesgen Worku Gudayu ${ }^{2}$ and Melese Siyoum Desta ${ }^{3}$
}

\begin{abstract}
Background: In Ethiopia, nearly half of the mothers who were booked for antenatal care, who supposed to have institutional delivery, gave home delivery nationally. Home delivery accounts majority while few of childbirth were attended by the skilled provider in Amhara regional state. This study aimed to determine the proportion of home delivery and associated factors among antenatal care booked women who gave childbirth in the past 1 year in Debremarkos Town, Northwest Ethiopia.
\end{abstract}

Methods: A community-based Cross sectional study was conducted from January 1st_ 25th 2016. Epi Info version 7 was used to determine a total sample size of 518 and simple random sampling procedure was employed. Data was collected through an interview by using pretested structured questionnaire. Data were entered into Epi Info version 7, cleaned and exported to SPSS version 21 for analysis. A p-value less than or equals to 0.05 at 95\% Confidence Intervals of odds ratio were taken as significance level in the multivariable model.

Results: A total of 127 (25.3\%) women gave childbirth at home. Un-attending formal education (Adjusted Odds Ratio $=7.56,95 \% \mathrm{Cl}:[3.28,17.44])$, absence of health facility within 30 min distance (AOR $=3.41,95 \% \mathrm{Cl}:[1.42,8.20])$, not exposed to media (AOR $=4.46,95 \% \mathrm{Cl}:[2.09,9.49])$, Unplanned pregnancy (AOR $=3.47,95 \% \mathrm{Cl}[1.82,6.61])$, attending $A N C$ at health post $(A O R=5.45,95 \% \mathrm{Cl}:(1.21,24.49)$ and health center $(A O R=2.74,95 \% \mathrm{Cl}[1.29,5.82])$, perceived privacy during ANC $(A O R=3.69[1.25,10.91])$ and less than four times $A N C$ visit $(A O R=5.04,95 \% \mathrm{Cl}(2.30$, 11.04]) were significantly associated with home delivery.

Conclusions: Home delivery in this study was found to be low. Educational level, media exposure, geographic access to a health facility, Unplanned pregnancy, an institution where ANC was booked, perceived privacy during ANC and number of ANC visit were found to be determinants of home delivery. Health institutions, health professionals, policy makers, community leaders and all concerned with the planning and implementation of maternity care in Ethiopia need to consider these associations in implementing services and providing care, for pregnant women.

Keywords: Antenatal care, Home delivery, Institutional delivery, Debremarkos, Ethiopia

\footnotetext{
* Correspondence: habtekebe@gmail.com

${ }^{1}$ Midwifery Department, College of Medical and Health Sciences, Wollega

University, P.O. Box 395, Nekemte, Ethiopia

Full list of author information is available at the end of the article
} 


\section{Background}

Antenatal care is complex of interventions that a pregnant woman receives from related health care services to prevent, identify and treat complications and as well help a lady approach pregnancy and birth as positive experiences [1]. Antenatal care, skilled personnel attended delivery and postnatal care services have a crucial role in the reduction of both maternal and perinatal mortality, also they were indicators of progress toward achievement of fifth MDGs and currently also included under third SDGs. Levels of antenatal care have increased in many parts of the world, though only $46 \%$ of low-income countries benefited from attended delivery. Skilled attendant at delivery is advocated as a single most important factor to prevent maternal mortality $[2,3]$.

Every day over 800 maternal deaths occur worldwide, and $99 \%$ of this death is occurring in developing countries secondary to preventable causes, making maternal mortality the health statistic with the largest inequality between developed and developing countries [4]. These high maternal mortalities occur due to various direct and indirect causes, which indicate poor-quality maternal health care [5-7]. Since the launch of the motherhood initiatives, maternal mortality was taken as social injustice and health disadvantages. This consensus raised the attention and commitment of providing accessible and high-quality maternity care, even though the problem still needs more attention [8].

Although safe motherhood service has been on implementation for about three decades, overall global maternal mortality ratio was decreased from 422 in 1980 to 251 in 2008 and to 210 per 100,000 live birth in 2013 [9, 10], yet average annual reduction in Africa (1.6\%) and subSaharan African (SSA) (1.7\%) region was slowest of all other regions $[11,12]$. In SSA, the burden of low-skilled birth attendant has been significant. In this region, $70 \%$ of births from poorest women occur at home and among this $56 \%$ of them were unattended [13].

Ethiopia is also among countries from which high maternal mortality has been occurring. Joint report of the maternal mortality estimates from WHO and UNICEF identified a reduction of maternal mortality to 420 per 100,000 live birth with a very wide confidence interval from 240 to 720 . Antenatal care coverage at least one time and at least four times remain low even though there were encouraging improvement from 27 and 10\% in 2000 to 42 and $19.1 \%$ in 2011 consecutively. The 2014 report of Central Statistical Agency revealed as Antenatal Care coverage reached $57.2 \%$ (at least one time) and $31.6 \%$ (at least four times), while the proportion of births attended by skilled health personnel improving slowly from 10\% in 2011 and 14.5 in 2014 [5, 14, 15].

This discrepancy between ANC coverage and the skilled attendant at birth clearly indicates whatever women get ANC services, enormously they prefer or forced to choice home or unattended delivery. Comparative descriptive analysis demonstrated high gap between the proportion of antenatal care utilization and institutional delivery by the same individuals, which ranges 27-95\% verses 4-45\% [3].

The burden of home delivery, mainly that of unattended delivery is not only limited to a maternal health problem, rather it also ends up with perinatal and neonatal morbidity and mortality. Perinatal mortality found to be $21 \%$ higher in home delivery as compared to institutional delivery in SSA [16]. The opposite is true in developed country, there was no significant difference between home delivery and hospital delivery regarding perinatal or neonatal mortality, where midwives provide both hospital and home care [17].

Various reviews from a different part of the world reported factors affecting utilization of ANC service and place of delivery [18], but there was no adequate literature which answers about the reason that ANC booked women prefer home delivery or forced to do so in the study area as well in the country. This study was aimed to determine the proportion of home delivery and tried to explore factors determining home delivery among antenatal care booked women.

\section{Methods}

\section{Study setting and populations}

A community-based quantitative cross sectional study was conducted from January 1 to 25th, 2016 in Debremarkos town. Debremarkos town is located at $299 \mathrm{~km}$ Northwest of Addis Ababa and 265killometrs Southeast of the Regional capital city, Bahir Dar and it is the capital city of the East Gojjam Zone. It is found in Guzamin district and divided into seven urban kebeles (smallest administrative level) which having two rural goxs. Based on the 2007 national census, Guzamin district has a total population of 270,578 and Debremarkos town has a total population size of 62,469 of which $47.9 \%$ were male and $52.1 \%$ were females and by $2015 / 16$ it was projected to be 107,234 [19].

Participants of this study were selected randomly from women who were booked for antenatal care and gave childbirth, irrespective of the outcome, within 1 year prior to January 2016. Limiting the participants to only 1 -year period was made to minimize potential recall bias.

\section{Study variables}

Place of delivery, specifically home delivery is outcome variable, while others like sociodemographic, programmatic related, women's perceptions of quality of care during antenatal care, knowledge of the women and obstetric variables are explanatory variables included in the 
study. Women who answered more than the mean of knowledge questions about danger sign during pregnancy and delivery, services given during pregnancy and deliveries, importance of the services and complications during pregnancy and delivery were considered as knowledgeable while those who answered less than mean were taken as don't know.

\section{Sample size and sampling procedures}

A sample size of 518 was calculated using Epi Info Stat Calc version 7 population survey by taking assumptions of population size $<10,000,95 \%$ confidence interval $(0.05$ type one error), Expected proportion of home delivery (68.4\%) from previous study in Amhara region [20], confidence limit (margin of error) 4 and 5\% nonresponse rate. A total of 3265 women who had booked for ANC and gave childbirth within 1 year since January 2015 were identified by census all over 7 kebeles of the town. Then each household having those mothers were coded. Simple Random Sampling was employed using computer generated random number to identify 518 samples after developing frame having a list of individual's house number which was given during census. Finally identified study participants were interviewed by home to home visit.

\section{Data collection tools and procedures}

Data were collected using pretested, structured and semi-structured interviewer-administered questionnaire in the Amharic language which contains six parts. The questionnaire was first developed in English and then translated into local language Amharic by researchers. Then it was translated back to English by other people who are proficient in both languages to maintain the consistency and content of the questionnaire.

Data was collected by seven graduating class Bachelor Science Extension Midwifery students from Debremarkos University and two Bachelor Science Midwives from Debremarkos Referral Hospital were assigned to supervise the data collection process. Training was provided for 2 days for data collectors and supervisors regarding the objectives of the study, data collection method, and tools, informed consent means and significance of the study. During data collection, each data collectors was supervised for any difficulties and direction and necessary correction was provided. Collected questionnaires were checked for completeness and on spot corrective measure was taken both by data collectors and supervisors. Daily meeting was conducted between data collectors, supervisors and principal investigator for discussion regarding presenting difficulties and to assess the progress of data collection.

\section{Data processing and analysis}

All collected questionnaires were rechecked for completeness and coded. Then these data were entered and cleaned using Epi Info 7 software and exported to SPSS version 21 for analysis. Bivariable and multivariable logistic regression were employed to identify an association between home delivery and other independent variables. All variables significantly associated with home delivery at less than or equals to $0.2 p$-values in the bivariable logistic regression model were fitted into the multivariable logistic regression model to control the effect of confounding variables.

Multivariable analysis using backward stepwise logistic regression technique was done to evaluate the independent effect of each covariate on home delivery by controlling the effect of others. Variable having $P$-value less than or equals to 0.05 in the multivariable logistic regression analysis was considered as determinant factors for home delivery. The adjusted odd ratios with the 95\%Confidence Intervals were reported. Before the actual logistic regression analysis was done, the necessary assumption of logistic regression model was checked by using Hosmer-Lemeshow test of goodness of fit which has a chi-square distribution. For further analysis, descriptive statistics like frequencies and cross tabulation were performed. Tables and bar chart were used to present the findings of the study.

The whole work of this study adhered to STROBE guidelines for the cross sectional/observational study.

\section{Result}

A total of 502 women who had booked for antenatal care visit for their last pregnancy and gave birth within 1 year prior to the survey were interviewed which makes response rate of $96.9 \%$, while the remaining 16 selected samples were not present at home during data collection and considered as none respondents after three continuative re-visit.

\section{Sociodemographic Characteristics of participants}

About 421 (83.9\%) of the participants were urban in residency while the remaining were from rural goxs of urban kebeles. Their age ranges from 18 to 50 with a median age of 30 and Interquartile range \pm 8 . The majority of the participants belongs to Amhara ethnicity 426 (84.90\%) and Ethiopian Orthodox tewahido religion 481 (95.85\%). More than half of the respondents who reported to have formal education were secondary school and above 262 (52.2\%). Regarding marital status majority of them were married $444(88.4 \%)$ and $218(43.4 \%)$ of the participant women were a housewife and 133 (26.5\%) of them were a government employee in occupation. 333 (71.8\%) of husbands/ partners' of the respondents were educated to secondary and above while 201 (43\%) of them were a government employee in occupation. 
Around one-third 170 (33.9\%) of the respondents' family size was three and fewer persons. Nearly one fourth $130(25.9 \%)$ of the household income was above 4000 Ethiopian birrs per month, while 132 (30.2\%) of them got $\leq 2000$ Ethiopian birr per month.

The majority of the respondents 442 (88\%) had geographic access to a health facility in the village, among these 214 (48.4\%) could be reached within $5 \mathrm{~min}$ by vehicle. About two-third of the respondents 332 (66.1\%) were exposed to at least one means of media, while the remaining were not exposed (see Table 1).

\section{Past Obstetrics Characteristics of the respondents}

Regarding age at first marriage, 114 (23.7\%) of the respondents were married before the age of 18 . Two hundred eighty-two (56.2\%) of the responding women were first pregnant while their age was between 19 and 24. About $74(14.7 \%)$ of the respondents were delivered five and more times. 143 (28.5\%) of the respondents had experience of prolonged labor before the index delivery and nearly half 178 (51.6\%) of the previous deliveries were took place at home. About one-third 119 (33.8\%) of individuals had experienced at least one of bad obstetric history before their last pregnancy.

Regarding their last pregnancy, 382 (76.1\%) women reported that their last pregnancy was planned and majority $347(69.1 \%)$ of them attended ANC at the health center. $401(79.9 \%)$ of the respondents were started ANC before 16 weeks of gestational age, and only 168 (33.5\%) of the respondents were attended four and above visits of antenatal care (see Table 2).

\section{Perceived characteristics of ANC and knowledge of the participants}

The majority of the respondents 462 (92.0\%) and 492 (98.0\%) reported that they received an explanation from providers about their health condition and what to expect during labor and delivery respectively. Similarly, a great deal of responding women reported that they received respect and privacy from the service provider during antenatal care.

Concerning behavior of the care providers about 226 (45\%) of them revealed as they have good behavior and only $19(3.8 \%)$ of respondents reported quality of ANC as poor while the rest said it was satisfactory and good. About 319 (63.5\%) of the respondents received ANC service in average within $30 \mathrm{~min}$ of their arrival to the health facility. Almost all of the respondents reported as they were advised on the importance of institutional delivery, danger signs during pregnancy and delivery during ANC 444 (88.4\%) and the rest during a home visit by $\mathrm{HEW}$.

Knowledge of the participants refers to the participants' understanding of the advice they received from
Table 1 Sociodemographic Characteristics of study participants in Debremarkos town, North West Ethiopia, January 2016 $(n=502)$

\begin{tabular}{|c|c|c|}
\hline Characteristics & Frequency & Percentage \\
\hline \multicolumn{3}{|l|}{ Maternal residence } \\
\hline Urban & 421 & 83.9 \\
\hline Rural & 81 & 16.1 \\
\hline \multicolumn{3}{|c|}{ Maternal age in year (Median = 30, IQR = 8) } \\
\hline $15-19$ & 4 & 0.8 \\
\hline $20-24$ & 54 & 10.7 \\
\hline $25-29$ & 158 & 31.5 \\
\hline $30-34$ & 145 & 28.9 \\
\hline 35 and above & 141 & 28.1 \\
\hline \multicolumn{3}{|l|}{ Maternal Marital Status } \\
\hline Single & 27 & 5.4 \\
\hline Married & 444 & 88.4 \\
\hline Divorced/Widowed & 31 & 6.2 \\
\hline \multicolumn{3}{|l|}{ Maternal Ethnicity } \\
\hline Amhara & 481 & 95.8 \\
\hline Oromo & 17 & 3.4 \\
\hline Others $^{a}$ & 4 & 0.8 \\
\hline \multicolumn{3}{|l|}{ Maternal Religion } \\
\hline Orthodox & 426 & 84.9 \\
\hline Protestant & 20 & 4.0 \\
\hline Muslim & 56 & 11.1 \\
\hline \multicolumn{3}{|l|}{ Maternal Educational Status } \\
\hline No Formal education & 118 & 23.5 \\
\hline Primary education & 122 & 24.3 \\
\hline Secondary and above & 262 & 52.2 \\
\hline \multicolumn{3}{|l|}{ Maternal Occupation } \\
\hline Housewife & 218 & 43.4 \\
\hline Gov't employee & 133 & 26.5 \\
\hline NGO employee & 23 & 4.6 \\
\hline Private Business & 103 & 20.5 \\
\hline Student & 25 & 5.0 \\
\hline \multicolumn{3}{|c|}{ Husband/ Partner Educational status $(n=464)$} \\
\hline No formal education & 109 & 23.5 \\
\hline Primary Education & 22 & 4.7 \\
\hline Secondary and above & 333 & 71.8 \\
\hline \multicolumn{3}{|c|}{ Husband/Partner Occupation $(n=467)$} \\
\hline Farmer & 82 & 17.6 \\
\hline Gov't employee & 201 & 43.0 \\
\hline NGO employee & 52 & 11.1 \\
\hline Private Business & 120 & 25.7 \\
\hline Others & 12 & 2.6 \\
\hline
\end{tabular}

House Hold Income per month in Birr 
Table 1 Sociodemographic Characteristics of study participants in Debremarkos town, North West Ethiopia, January 2016 $(n=502)$ (Continued)

\begin{tabular}{lll}
\hline$\leq 2000$ & 152 & 30.3 \\
$2001-4000$ & 220 & 43.8 \\
$\geq 4000$ & 130 & 25.9
\end{tabular}

Presence of Health Facility in the village within 30 min distance on foot

$\begin{array}{lll}\text { No } & 60 & 12.0 \\ \text { Yes } & 442 & 88.0\end{array}$

Time to reach Health facility by vehicle/min

(Mean \pm SD $=8.60 \pm 5.75)(n=442)$

$\begin{array}{lll}\leq 5 \text { min } & 214 & 48.4 \\ 5-10 \text { min } & 147 & 33.3 \\ >10 \text { min } & 81 & 18.3 \\ \text { Family Size } & & \\ \leq 3 \text { person } & 170 & 33.9 \\ 4-5 \text { person } & 204 & 40.6 \\ \geq 6 \text { person } & 128 & 25.5 \\ \text { Media Exposure } & & \\ \text { Exposed to at least one source of media } & 332 & 66.1 \\ \text { Not exposed to any media source } & 170 & 33.9\end{array}$

Tigraway, Gurage

${ }^{\mathrm{b}}$ Daily laborer \& No occupation

the health care providers during ANC or home visit. Based on this score they acquired from the total knowledge assessing questions, the respondents classified as knowledgeable or not, taking the mean score as differentiation for knowledge. Among 33 knowledge questions respondents were asked on danger sign, services, complications during pregnancy and delivery 214 (42.6\%) of the respondents scored correct answers for the questions above mean (which was 18) of the overall correct response, while 288 (57.4\%) of them scored less than mean of knowledge questions score. Concerning ANC service providers 316 (62.9\%) received from Midwives and 59 (11.8\%) of them from HEW. Among these $424(84.5 \%)$ of the respondents received highquality ANC from skilled health care providers while the remaining received comparably low-quality ANC from HEW (see Table 3).

\section{Maternal decision power on health care}

409 (86.1\%) individuals reported that they have discussed with their husband or partner about the place of delivery and majority of them 461 (91.8\%) preferred to deliver at health facility while comparably 424 (90.6\%) of husbands preferred the same place. Regarding delivery attendant $16(3.2 \%)$ of respondents and 30 (6.4\%) of husbands preferred TBA and one of family members respectively. Nearly three fourth $383(76.3 \%)$ of the final decision regarding the place of delivery was given by
Table 2 Past Obstetrics Characteristics of study participants in Debremarkos town, North West Ethiopia, January 2016.

\begin{tabular}{|c|c|c|}
\hline Characteristics & Frequency & Percentage \\
\hline \multicolumn{3}{|c|}{ Age at First Marriage (Mean $\pm S D=21.03 \pm 3.43$ ) } \\
\hline$<18$ Years & 114 & 23.7 \\
\hline$\geq 18$ Years & 368 & 76.3 \\
\hline \multicolumn{3}{|c|}{ Age at first pregnancy (Mean $\pm S D=23.45 \pm 4.07$ ) } \\
\hline$\leq 18$ years & 52 & 10.4 \\
\hline 19-24 years & 282 & 56.2 \\
\hline $25-30$ years & 136 & 27.1 \\
\hline Above30years & 32 & 6.4 \\
\hline \multicolumn{3}{|c|}{ Number of pregnancy } \\
\hline । & 153 & 30.5 \\
\hline$\|-I V$ & 249 & 49.6 \\
\hline V & 100 & 19.9 \\
\hline \multicolumn{3}{|c|}{ Number of delivery } \\
\hline$\leq 4$ & 428 & 85.3 \\
\hline$\geq 5$ & 74 & 14.7 \\
\hline
\end{tabular}

Experience of Prolonged labor greater than $12 \mathrm{~h}$ previously

$\begin{array}{lrr}\text { No } & 359 & 71.5 \\ \text { Yes } & 143 & 28.5 \\ \text { Previous place of delivery }(n=345) & \\ \text { Health facility } & 167 & 48.4 \\ \text { Home } & 178 & 51.6\end{array}$

Experience of Bad Obstetrics History $(n=352)$

$\begin{array}{lll}\text { No } & 233 & 66.2\end{array}$

$\begin{array}{lll}\text { Yes } & 119 & 33.8\end{array}$

Pregnancy Plan

$\begin{array}{lll}\text { Unplanned } & 120 & 23.9\end{array}$

$\begin{array}{lll}\text { Planned } & 382 & 76.1\end{array}$

Place where ANC attended

$\begin{array}{lll}\text { Health Post } & 26 & 5.2 \\ \text { Health Center } & 347 & 69.1 \\ \text { Hospital } & 125 & 24.9 \\ \text { Others }^{\mathrm{a}} & 4 & 0.8\end{array}$

GA at first ANC visit

Before 16 weeks $\quad 401$

16-28 weeks $\quad 94 \quad 18.7$

$\begin{array}{lll}\text { After } 28 \text { weeks } & 7 & 1.4\end{array}$

Number of ANC visit completed

$\begin{array}{lll}\text { One } & 18 & 3.6\end{array}$

Two and Three $\quad 316 \quad 62.9$

Four and above $\quad 168 \quad 33.5$ 
Table 3 Counseling and communication with health providers during ANC, and perceived behavior of health care providers in Debremarkos town, North West Ethiopia, January $2016(N=502)$

\begin{tabular}{lcr}
\hline Characteristics & Number & Percen \\
\hline Providers explained your condition in an understandable way \\
No & 40 & 8.0 \\
Yes & 462 & 92.0
\end{tabular}

Providers explained what to expect during labor and delivery

$\begin{array}{lll}\text { No } & 10 & 2.0 \\ \text { Yes } & 492 & 98.0\end{array}$

Providers listened to your questions or concerns

$\begin{array}{lll}\text { No } & 63 & 12.5 \\ \text { Yes } & 439 & 87.5\end{array}$

Did the providers respect you

$\begin{array}{lll}\text { No } & 30 & 6.0 \\ \text { Yes } & 472 & 94.0\end{array}$

Privacy protected during the examinations

$\begin{array}{lll}\text { No } & 51 & 10.2 \\ \text { Yes } & 451 & 89.8\end{array}$

Perceived Behavior of ANC service providers

$\begin{array}{lll}\text { Very Good } & 208 & 41.4 \\ \text { Good } & 226 & 45.0 \\ \text { Fair } & 55 & 11.0 \\ \text { Bad } & 13 & 2.6\end{array}$

Time taken to get ANC

$30 \mathrm{~min}$ and less $\quad 319$

31-59 min $\quad 89 \quad 17.7$

60 min and more $\quad 94 \quad 18.8$

Perceived quality of ANC

$\begin{array}{lll}\text { Good } & 383 & 76.3 \\ \text { Satisfactory } & 100 & 19.9 \\ \text { Poor } & 19 & 3.8\end{array}$

Timing of advice on ID \& danger sign during pregnancy and delivery

$\begin{array}{lll}\text { During ANC } & 444 & 88.4 \\ \text { During home visit by HEW } & 57 & 11.4\end{array}$

Fear to be exposed during delivery

\begin{tabular}{|c|c|c|}
\hline Yes & 145 & 28.9 \\
\hline No & 350 & 69.7 \\
\hline Others ${ }^{a}$ & 7 & 1.4 \\
\hline
\end{tabular}

$\begin{array}{lll}\text { Midwives } & 316 & 62.9 \\ \text { Nurses } & 85 & 16.9 \\ \text { Medical Doctors } & 18 & 3.6 \\ \text { Public Health Officers } & 6 & 1.2 \\ \text { HEW } & 59 & 11.8 \\ \text { Don't know } & 18 & 3.6\end{array}$

Table 3 Counseling and communication with health providers during ANC, and perceived behavior of health care providers in Debremarkos town, North West Ethiopia, January 2016 ( $N=502)$ (Continued)

\begin{tabular}{lll}
\hline Knowledge of Participants & & \\
Don't know & 288 & 57.4 \\
Knows & 214 & 42.6 \\
\hline${ }^{\mathrm{a} M i s s i n g}$ &
\end{tabular}

both respondent and her husband, while 93 (18.5\%) of the respondents gave by themselves on the place of delivery. 54 (10.7\%) of a financial decision for costs related to pregnancy and delivery were decided only by their husband (see Table 4).

\section{Home delivery and reasons given}

From all respondents, 127 (25.3\%, 95\% CI [21.6, 28.7]) of them gave childbirth at home while 375 (74.7\%) of the respondents delivered at a health facility. Majority 107 $(84.3 \%)$ of home deliveries took place at women's own home.

Of the total home deliveries, 74 (58.3\%) of them were assisted by women's relatives, nearly one fourth 34 (26.8\%) of these deliveries were not attended and the remaining 19 (14.9\%) of deliveries were assisted by respondents' mother, husband, and TBAs (see Table 5).

Responding women gave a variety of reasons for providing home delivery. Among these 'labor was simple and fast' 97 (76.4\%), 'wishes to deliver at home where relatives are nearby' 45 (35.4\%) and 'providing home delivery is our culture' 35 (27.6\%) were leading (see Fig. 1).

\section{Determinants of home deliveries}

In Bivariable logistic regression marital status, maternal occupation, maternal residence, maternal educational level, presence of health facility in the village within $30 \mathrm{~min}$, media exposure, family size, maternal age at first pregnancy, number of delivery, experience of prolonged labor, planned pregnancy, facility at which ANC attended, number of ANC visit completed, GA at first ANC visit, maternal knowledge on maternity service, perceived respect during ANC, perceived privacy during ANC, time to wait to get ANC in minutes, decision maker on cost needed for referral and decision maker on place of delivery were the factors found to be statistically significantly associated with home delivery.

All variables associated with home delivery in bivariable analysis at $0.2 P$-value were fitted to multivariable logistic regression model in order to control confounding factors. Accordingly un-attending formal education $(\mathrm{AOR}=7.56,95 \% \mathrm{CI}$ : $[3.28,17.44])$, absence of health facility within $30 \mathrm{~min}$ distance $(\mathrm{AOR}=3.41$, 95\% CI: $[1.42,8.20])$, none exposed to media 
Table 4 Discussion habit and Maternal decision power on the place of delivery in Debremarkos town, North West Ethiopia, January $2016(N=502)$

\begin{tabular}{lc}
\hline Characteristics & Number \\
\hline Discussed with your husband/partner on place of delivery? $(N=475)$
\end{tabular}

$\begin{array}{lll}\text { No } & 66 & 13.9 \\ \text { Yes } & 409 & 86.1\end{array}$

Where did you choice to deliver

$\begin{array}{lll}\text { Home } & 35 & 7.0 \\ \text { Health Facility } & 461 & 91.8 \\ \text { Others }^{\mathrm{a}} & 6 & 1.2\end{array}$

Where did your husband prefer you to deliver (468)

$\begin{array}{lll}\text { Home } & 35 & 7.5 \\ \text { Health Facility }^{\text {Others }}{ }^{\mathrm{a}} & 424 & 90.6 \\ & 9 & 1.9\end{array}$

Whom did you prefer to attend your delivery

$\begin{array}{lll}\text { Skilled Health Professional } & 465 & 92.6 \\ \text { Trained TBA } & 16 & 3.2 \\ \text { One of my family member } & 21 & 4.2\end{array}$

Whom did your husband choice to attend your delivery

$\begin{array}{lll}\text { Skilled Health Professionals } & 432 & 91.9 \\ \text { Trained TBA } & 8 & 1.7 \\ \text { One of my family member } & 30 & 6.4\end{array}$

Where did other community members prefer to you to deliver

$\begin{array}{lll}\text { Home } & 33 & 6.6 \\ \text { Health Facility } & 469 & 93.4\end{array}$

Where did other family members prefer you to deliver

$\begin{array}{lll}\text { Home } & 75 & 14.9 \\ \text { Health Facility } & 425 & 84.7 \\ \text { Others }^{\mathrm{a}} & 2 & 0.4\end{array}$

Who gave final decision on place of delivery

$\begin{array}{lll}\text { Me } & 93 & 18.5 \\ \text { My husband } & 16 & 3.2 \\ \text { Both me and my husband } & 383 & 76.3 \\ \text { My Parents } & 10 & 2.0\end{array}$

Who decide on costs related to pregnancy and delivery

\begin{tabular}{lll} 
Me & 41 & 8.2 \\
My husband & 54 & 10.7 \\
Both me and my husband & 385 & 76.7 \\
My Parents & 22 & 4.4 \\
\hline aPrivate clinic & &
\end{tabular}

$(\mathrm{AOR}=4.46,95 \% \mathrm{CI}:[2.09,9.49])$, unplanned pregnancy $(\mathrm{AOR}=3.47,95 \% \mathrm{CI}[1.82,6.61])$, attending $\mathrm{ANC}$ at health post $(\mathrm{AOR}=5.45,95 \% \mathrm{CI}:(1.21,24.49)$, health center $(\mathrm{AOR}=2.74,95 \%$ CI $[1.29,5.82])$, perceived privacy during ANC $(\mathrm{AOR}=3.69[1.25,10.91])$ and less than four times $\mathrm{ANC}$ visit $(\mathrm{AOR}=5.04,95 \% \mathrm{CI}(2.30$,
Table 5 Ideas given on institutional delivery and actual place of delivery in Debremarkos town, North West Ethiopia, January $2016(n=502)$

\begin{tabular}{|c|c|c|}
\hline Characteristics & Number & Percent \\
\hline \multicolumn{3}{|c|}{ Maternal idea on institutional delivery } \\
\hline It is Necessary & 498 & 99.2 \\
\hline Not Necessary & 4 & 0.8 \\
\hline \multicolumn{3}{|c|}{ Family's idea on necessity of institutional delivery } \\
\hline It is Necessary & 433 & 86.2 \\
\hline Not Necessary & 29 & 5.8 \\
\hline Not Customary & 40 & 8.0 \\
\hline \multicolumn{3}{|l|}{ Place of Current Delivery } \\
\hline Health Facility & 375 & 74.7 \\
\hline Home & 127 & 25.3 \\
\hline \multicolumn{3}{|c|}{ Place at home delivery specifically $(N=127)$} \\
\hline My own home & 107 & 84.3 \\
\hline My parents' home & 16 & 16.6 \\
\hline Religious home & 4 & 3.1 \\
\hline \multicolumn{3}{|c|}{ Delivery Attendant for home delivery $(N=127)$} \\
\hline Relatives & 74 & 58.3 \\
\hline No one & 34 & 26.8 \\
\hline Others $^{a}$ & 19 & 14.9 \\
\hline \multicolumn{3}{|c|}{ Which Health Institution for Health facility delivery $(N=375)$} \\
\hline Public Hospital & 165 & 44.0 \\
\hline Health Center & 198 & 52.8 \\
\hline Private and NGO clinics & 12 & 3.2 \\
\hline
\end{tabular}

${ }^{a}$ My mother, my husband, TBAs

11.04]) were factors found independently associated with home delivery at $p$-value of less than or equals to 0.05 (see Table 6).

\section{Discussion}

This study was aimed to assess the proportion of home delivery and associated factors among ANC booked and gave birth in the last 12 months preceding survey. It is reasonable to assess proportion and associated factors of home delivery among ANC utilized individuals in an urban community where having more infrastructures in healthcare facilities than rural areas, and thus, usage of institutional delivery is expected to be high.

The result of this study revealed that 127 (25.3\%, with 95\% CI [21.6, 28.7]) of total respondents were given delivery at home. The proportion of home delivery in this study is lower than 2011 EDHS (76.25\% National and $89.3 \%$ of Amhara region) and study done in Fogera district of Northwest Ethiopia which was $68.4 \%$ of total participants. This large difference could be due to the difference in residency, as most of the participant in those studies were residents from rural [21, 22]. 


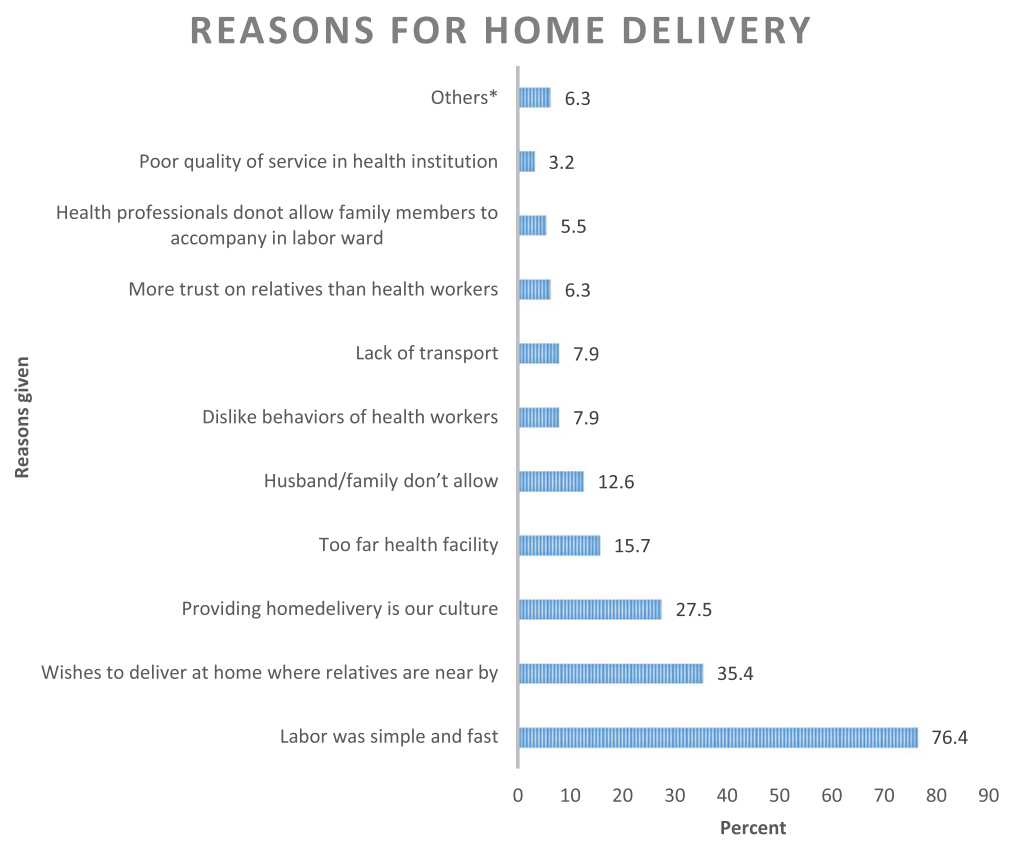

Fig. 1 Reasons given by respondents on home delivery in Debremarkos, North West Ethiopia, January $2016(n=127)$. *Fear of HIV infection, health facility was close and I was alone

The magnitude of home delivery in this study is also lower than the result of a study done 4 years back in the same setting on the preference of place of delivery in which $37.7 \%$ of them delivered at home. It is also lower than studies done in other parts of Ethiopia [22-30] which could be because of time and study subjects' difference as these studies included individuals who did not have antenatal care follow up which is one of the most known predictors of home delivery. A lot of contributions had been made to change the awareness of women's and communities' on the utilization of institutional delivery which might result in this decreased home delivery than these mentioned studies. It might be due to the fact that most of the respondents and majority $(86.2 \%)$ of their family believed in the necessity of institutional delivery in this study.

It is also lower than studies done in other developing countries like Kenya [31], Tanzania [32], Ghana [33], Nigeria [34], Nepal [35], this might be due to presence of a difference in the health service delivery system, sociocultural difference, economic or study setting difference.

It is consistent with a study done in Bahir Dar city administration and another African country like Nigeria and Senegal. This might be because the majority of the respondents were from urban and ANC booked [36-38].

In another study from Nepal [39] proportion of home delivery $(15 \%)$ was lower than this study, which might be because of difference in study design. The study from Nepal had a nature of follow-up in which participants were asked about their preference of place of delivery, which could have imposed them to had more institutional delivery than home.

Educational status of the responding women and husband was reported as a determinant factor to home delivery from the vast majority of studies done both in our country and abroad [21-30, 34, 40, 41]. The result of this study also supports those findings as being uneducated was significantly associated with home delivery. Mothers who did not have any formal education were seven times $(\mathrm{AOR}=7.56,95 \% \mathrm{CI}$ : $[3.28,17.44])$, more likely to deliver at home than those educated to secondary and above educational levels. Education is a major key strategy to enhance health care service utilization. However, if there is no universal access to education it would be the big gap between educated and not in understanding the difficulties of laboring and childbirth as well complications related to unattended delivery. Being educated increase the awareness of preventive health care services and the receptive ability for new information. Education could also enhance women autonomy which enables them to discuss and determine on the place of delivery. Due to these facts, women who did not attend any formal education ended up with home delivery than their counterparts.

Media exposure was also another determinant of home delivery with four times $(\mathrm{AOR}=4.46,95 \% \mathrm{CI}$ : $[2.09,9.49])$ likelihood of delivering at home among not exposed group than exposed ones. This is in line with the studies done in Gondar and Holeta. This could be due to the fact that individuals whom having media 
Table 6 Determinants of Home delivery from backward stepwise (Wald) logistic regression in Debremarkos, North West Ethiopia, January 2016

\begin{tabular}{|c|c|c|c|c|c|}
\hline \multirow[t]{2}{*}{ Variables } & \multicolumn{2}{|c|}{ Place of delivery } & \multirow{2}{*}{$\begin{array}{l}\text { Crude OR } \\
\text { OR ( } 95 \% \mathrm{Cl})\end{array}$} & \multirow{2}{*}{$\begin{array}{l}\text { Adjusted OR } \\
\text { OR (95\% Cl) }\end{array}$} & \multirow[t]{2}{*}{$P$-Value } \\
\hline & Home (\%) & $\mathrm{HI}(\%)$ & & & \\
\hline \multicolumn{6}{|l|}{ Marital status } \\
\hline Single & $12(44.4)$ & $15(55.6)$ & $2.5(1.17,5.7)$ & $*$ & \\
\hline Divorced/Widowed & $10(32.3)$ & $21(67.7)$ & $1.5(0.7,3.4)$ & & \\
\hline Married & 105 (23.6) & $339(76.4)$ & 1 & & \\
\hline \multicolumn{6}{|l|}{ Maternal education level } \\
\hline No Formal Education & $78(66.1)$ & $40(33.9)$ & $16.97(9.77,29.45)$ & $7.56(3.28,17.44)$ & $<0.001$ \\
\hline Primary school & $22(18)$ & $100(82)$ & $1.9(1.04,3.52)$ & * & \\
\hline Secondary and above & $27(10.3)$ & $235(89.7)$ & 1 & 1 & \\
\hline \multicolumn{6}{|l|}{ Maternal Occupation } \\
\hline NGO/Gov't Employee & $12(7.7)$ & $144(92.3)$ & $0.13(0.07,0.26)$ & * & \\
\hline Private business & $23(23.3)$ & $80(77.7)$ & $0.47(0.27,0.81)$ & & \\
\hline Student & $10(40)$ & $15(60)$ & $1.10(0.47,2.57)$ & & \\
\hline Housewife & $82(37.6)$ & $136(62.4)$ & 1 & & \\
\hline \multicolumn{6}{|l|}{ Maternal Residency } \\
\hline Rural & $49(60.5)$ & $32(39.5)$ & $6.73(4.05,11.20)$ & * & \\
\hline Urban & $78(18.5)$ & $343(81.5)$ & 1 & & \\
\hline \multicolumn{6}{|c|}{ Presence of Health facility within $30^{\prime}$} \\
\hline No & $38(63.3)$ & $22(36.7)$ & $6.85(3.86,2.17)$ & $3.41(1.42,8.20)$ & 0.006 \\
\hline Yes & $89(20.1)$ & $353(79.9)$ & 1 & 1 & \\
\hline \multicolumn{6}{|l|}{ Family size in person } \\
\hline$\leq$ three & $36(21.2)$ & $134(78.8)$ & $0.28(0.17,0.46)$ & * & \\
\hline $4-5$ & $28(13.7)$ & $176(86.3)$ & $0.16(0.09,0.28)$ & & \\
\hline 6 and above & $63(49.2)$ & $65(50.8)$ & 1 & & \\
\hline \multicolumn{6}{|l|}{ Media Exposure } \\
\hline Not exposed & $95(55.9)$ & $75(44.1)$ & $11.87(7.40,19.10)$ & $4.46(2.09,9.49)$ & $<0.001$ \\
\hline Exposed & $32(9.6)$ & $300(90.4)$ & 1 & 1 & \\
\hline \multicolumn{6}{|c|}{ Maternal age at 1st pregnancy } \\
\hline$<18$ years & $31(59.6)$ & $21(40.4)$ & $5.44(2.99,9.90)$ & * & \\
\hline$\geq 18$ years & $96(21.3)$ & $354(78.7)$ & 1 & & \\
\hline \multicolumn{6}{|l|}{ Number of Parity/delivery } \\
\hline Four and less & $81(18.9)$ & $347(81.1)$ & $0.14(0.08,0.24)$ & * & \\
\hline Five and above & $46(62.2)$ & $28(37.8)$ & 1 & & \\
\hline \multicolumn{6}{|c|}{ Experience of Prolonged Labor greater than $12 \mathrm{~h}$} \\
\hline No & $82(22.8)$ & $277(77.2)$ & $0.64(0.42,0.99)$ & * & \\
\hline Yes & $45(31.5)$ & $98(68.5)$ & 1 & & \\
\hline \multicolumn{6}{|c|}{ Perceived respect during ANC } \\
\hline No & $20(66.7)$ & $10(33.3)$ & $6.68(4.07,11.4)$ & * & \\
\hline Yes & $107(22.7)$ & $365(77.3)$ & 1 & & \\
\hline \multicolumn{6}{|c|}{ Perceived privacy during ANC } \\
\hline No & $32(62.7)$ & $19(37.3)$ & $6.31(4.23,9.4)$ & $3.69(1.25,10.91)$ & 0.018 \\
\hline Yes & $95(21.1)$ & $356(78.9)$ & 1 & & \\
\hline
\end{tabular}


Table 6 Determinants of Home delivery from backward stepwise (Wald) logistic regression in Debremarkos, North West Ethiopia, January 2016 (Continued)

\begin{tabular}{|c|c|c|c|c|c|}
\hline \multicolumn{6}{|l|}{ Time to wait to get ANC in minutes } \\
\hline 30 and less & $95(29.8)$ & $224(70.2)$ & $2.42(1.6,3.6)$ & \multicolumn{2}{|l|}{$*$} \\
\hline $31-59$ & $18(20.2)$ & $71(79.8)$ & $1.44(0.88,2.4)$ & & \\
\hline 60 and more & $14(14.9)$ & $80(85.1)$ & 1 & & \\
\hline \multicolumn{6}{|l|}{ Pregnancy Plan } \\
\hline Unplanned & $64(53.3)$ & $56(46.7)$ & $5.78(3.69,9.06)$ & $3.47(1.82,6.61)$ & \multirow[t]{2}{*}{$<0.001$} \\
\hline Planned & $63(16.5)$ & $319(83.5)$ & 1 & 1 & \\
\hline \multicolumn{6}{|l|}{ Place where ANC attended } \\
\hline Health Post & $14(53.8)$ & $12(46.2)$ & $8.23(3.24,20.9)$ & $5.45(1.21,24.49)$ & 0.027 \\
\hline Health Center & $97(28)$ & $250(72)$ & $2.74(1.54,4.86)$ & $2.74(1.29,5.82)$ & 0.008 \\
\hline Public Hospital & $16(12.4)$ & $113(87.6)$ & 1 & 1 & \\
\hline \multicolumn{6}{|l|}{ GA at first ANC Visit } \\
\hline$\leq 16$ weeks & $80(20.0)$ & $321(80.0)$ & 1 & \multirow[t]{2}{*}{ * } & \\
\hline$>16$ weeks & $47(46.5)$ & $54(53.5)$ & $3.49(2.20,5.54)$ & & \\
\hline \multicolumn{6}{|l|}{ Number of ANC visit completed } \\
\hline One to three & $113(33.8)$ & $221(66.17)$ & $5.62(3.11,10.17)$ & $5.04(2.30,11.04)$ & \multirow[t]{5}{*}{$<0.001$} \\
\hline Four and above & $14(8.3)$ & $154(91.67)$ & 1 & 1 & \\
\hline \multicolumn{5}{|l|}{ Maternal Knowledge on maternity service } & \\
\hline Don't know & $93(39.7)$ & $141(60.3)$ & $4.54(2.91,7.08)$ & \multirow[t]{2}{*}{ * } & \\
\hline Knows & $34(12.7)$ & $234(87.3)$ & 1 & & \\
\hline \multicolumn{6}{|l|}{ Decision maker on cost needed for referral } \\
\hline $\mathrm{Me}$ & $20(48.8)$ & $21(51.2)$ & $4.6(2.9,7.1)$ & \multirow[t]{3}{*}{ * } & \\
\hline My husband/ other members of family & $41(53.9)$ & $35(46.1)$ & $5.66(4.0,7.9)$ & & \\
\hline Both me and my husband & $66(17.1)$ & $319(82.9)$ & 1 & & \\
\hline \multicolumn{6}{|l|}{ Decision maker on place of delivery } \\
\hline Me & $60(64.5)$ & $33(35.5)$ & $10.4(7.45,14.5)$ & \multirow[t]{3}{*}{ * } & \\
\hline My husband/ other members of family & $10(38.5)$ & $16(61.5)$ & $3.5(2.06,6.2)$ & & \\
\hline Both me and my husband & $57(14.9)$ & $326(85.1)$ & 1 & & \\
\hline
\end{tabular}

*-Variables which were not associated in backward stepwise multivariable logistic regression model, 1-Reference category

exposure had the ability to attend the awareness information on the importance of institutional delivery. Media also have the ability to change attitudes women and communities used to have on home delivery, as a result individual who not exposed to any source of media might be continued having home delivery more likely than those who exposed [23, 40].

Distance to the nearest health facility is also found to be associated with home delivery which was also reported from Jimma [42]. Individuals who lack geographic access to a health facility within a $30 \mathrm{~min}$ distance from women's home were three times $(\mathrm{AOR}=3.41,95 \% \mathrm{CI}:[1.42,8.20])$ more likely to have home delivery than their counterparts. Presumably the shorter the distance to the health facility the easier it is for a woman to get there, even if she has to walk. Pregnant mother's effort to travel on foot even when alternative traveling means is absent could be higher when the distance to a nearby health facility is shorter. Walking more kilometers is difficult in labor and it worse if the labor starts at night and very urging as most of the respondents gave it as a reason for home delivery.

Individuals who unplanned their last pregnancy had three $(\mathrm{AOR}=3.47,95 \% \mathrm{CI}[1.82,6.61])$ times likelihood of delivering at home than those who had planned their last pregnancy. Planning to have child needs mental, psychological and financial readiness. If one planned to have a child it means that this person fitted with these necessities. Again planned pregnancy indicates the presence of support person either the husband or partner. So as the pregnancy was planned and supported the probability of seeking institutional delivery increases. As a result, the likelihood of having home delivery could increase as one had unplanned pregnancy. 
Institutions, where ANC was attended, was also found to be one of the predictors of home delivery. Having ANC attendance at health post were five times $(\mathrm{AOR}=5.45,95 \mathrm{CI}:[1.21,24.49])$ more likely to deliver at home than whom attended at the hospital. Similarly, women who attended ANC at health center were three times $(\mathrm{AOR}=2.74,95 \% \mathrm{CI}[1.29,5.82])$ more likely to deliver at home than those who attended ANC at the hospital. Most of the health care providers in health center are midlevel educated and lack vast of experience, which might have helped them in counseling during antenatal care on the place of delivery. Though more investigations are needed, lack of experience, the absence of specialized health personnel in health post and health center and quality of ANC might be related to increased odds of home delivery.

Perceived lack of privacy during ANC increases the odds of home delivery four times than $(\mathrm{AOR}=3.69$, 95\% CI: $[1.25,10.91])$ who believed that they had been possessed privacy while ANC. It is in line with a report from Fogera district [20]. This might be because individuals who perceived a lack of privacy during ANC expect the same while they revisit health facility for childbirth. This could be also due to the fact that most of the respondents who perceived lack of privacy reported that they fear to expose their reproductive organs during delivery.

Similarly, as reported from other studies [20, 33, 39-41], increments in a number of ANC visit will result in less likelihood of delivering at home. Individuals who did not complete recommended four visits were five times $(\mathrm{AOR}=5.04,95 \% \mathrm{CI}(2.30,11.04])$ more likely to deliver at home when compared to those who had four and more ANC visits. This might be because number of the visit will increase the chance of having more awareness on the importance of institutional delivery. It also creates good opportunity on increasing counseling mothers got from health professionals which have great ability in minimizing home delivery. In addition, mostly practiced timing of advice on birth preparedness, especially on the place of delivery is in later gestational age and with increased number of visit.

\section{Limitation of the study}

Cross sectional nature of the study and some of the questions demanding in-depth interview and focused group discussion were simply addressed with openended questions due to different reasons.

\section{Conclusion and recommendation}

The proportion of home delivery in this study among women who were booked for antenatal care and gave childbirth within 1 year prior to survey time was found to be low. Un-attending formal education, presence of health facility within 30 min distance on foot, none exposed to media, unplanned pregnancy, attending antenatal care at health post and health center, perceived lack of privacy during antenatal care and antenatal care visits less than four times were factors found to be associated with home delivery significantly.

All concerned stakeholders need to take actions to alleviate the presenting problem by increasing educational opportunity for all women, enhancing geographic access to a health facility, awareness creation on the importance of media and utilization of family planning services in order to decrease home delivery for antenatal care booked women. The quality of antenatal care at health post and health centers has to be measured as individuals who received antenatal care at these facility tends to have more home delivery. In addition, there have to be strategies in which a number of antenatal care visit could be raised.

\section{Additional file}

Additional file 1: Questionnaire-English Version. This file presents the questionnaire used to collect data for this study. It contains separate six parts which presented in a total of nine pages including the title and an introcduction section. (DOCX $30 \mathrm{~kb}$ )

\section{Abbreviations}

ANC: Antenatal care; AOR: Adjusted Odds Ratios; Cl: Confidence interval; COR: Crudes Odds Ratios; CSA: Central Statistical Agency; EDHS: Ethiopian Demographic and Health survey; HIV: Human Immunodeficiency Virus; MDGs: Millennium Development Goals; OR: Odds Ratio; SDGs: Sustainable Development Goals; SSA: Sub Saharan Africa; UNFPA: United Nations Population Fund; WHO: World Health Organization

\section{Acknowledgements}

Heartfelt gratitudes to Mr. Ayenew Molla, Mr. Amare Workie, Mr. Firew Tekle and Mr. Tegene Legese for their invaluable comments. We extend our warm thanks to all supervisors, data collectors and study participants for their cooperation and support during the study period.

\section{Funding}

The financial support for this research project was obtained from University of Gondar, Research and Technology Transfer vice president office. The funder had no role in design of the study and collection, analysis, and interpretation of data and in writing the manuscript.

\section{Availability of data and materials}

The dataset analysed during the current study available from the corresponding author on reasonable request. The questionnaires that we developed for the collection of data is provided as Additional file 1.

\section{Authors' contributions}

HK conceived the study and wrote the proposal, facilitated data collection, analysis, data interpretation, drafted the final report write up and prepared manuscript. ZM, TW and MS participated in developing the tools and data collection process, data analysis and involved in report write up. All authors read and approved the final manuscript.

\section{Ethics approval and consent to participate}

Ethical clearance was obtained from Department of Midwifery, College of Medicine and Health Sciences, University of Gondar institutional review committee and letter of approval with reference number Midw/102896/07 was granted.

Then individual participants' written consent for participation was obtained. 


\section{Consent for publication}

Not applicable.

\section{Competing interests}

The authors declare that they have no competing interests.

\section{Publisher's Note}

Springer Nature remains neutral with regard to jurisdictional claims in published maps and institutional affiliations.

\section{Author details}

${ }^{1}$ Midwifery Department, College of Medical and Health Sciences, Wollega University, P.O. Box 395, Nekemte, Ethiopia. ${ }^{2}$ Midwifery Department, College of Medicine and Health Sciences, University of Gondar, P.O. Box 196, Gondar, Ethiopia. ${ }^{3}$ Midwifery Department, College of Medicine and Health Sciences, Hawassa University, P.O. Box 1560, Hawassa, Ethiopia.

Received: 14 July 2016 Accepted: 3 July 2017

Published online: 14 July 2017

\section{References}

1. Federal Ministry of Health, Ethiopia: Management protocol on selected obstetrics topics (FMOH) January, 2010.

2. Berhan Y, Berhan A. Skilled health personnel attended delivery as a proxy indicator for maternal and perinatal mortality: A systematic review. Ethiop J Health Sci. 2014;24:69-80.

3. Berhan $Y$, Berhan A. Antenatal Care as a means of increasing birth in the health facility and reducing maternal mortality: a systematic review. Ethiop J Health Sci. 2014;24:93-104.

4. World Health Statistics. A Wealth of Information on Global Public Health on global public healTh. Geneva: WHO; 2014.

5. United Nations Population Fund,. Trends in maternal health in Ethiopia: Challenges in achieving the MDG for maternal mortality: in-depth analysis of the EDHS 2000-2011, 2012.

6. Berhan Y, Berhan A. Causes of Maternal Mortality in Ethiopia: A Significant Decline in Abortion-Related Death. Ethiop J Health Sci. 2014;24:15-28.

7. Say L, Chou D, Gemmill A, Tunçalp Ö, Moller A-B, Daniels J, et al. Global causes of maternal death: a WHO systematic analysis. Lancet Glob Health. 2014;2(6):e323-e33.

8. Starrs AM. Safe motherhood initiative: 20 years and counting. Lancet. 2006; 368(9542):1130-2.

9. Hogan MC, Foreman K, Naghavi M, Ahn SY, Wang M, Makela SM, et al. Maternal mortality for 181 countries, 1980-2008: a systematic analysis of progress towards Millennium Development Goal 5. Lancet. 2010;375(9726):1609-23.

10. World Health Organization, Unicef. Trends in maternal mortality: 1990 to 2013: estimates by WHO, UNICEF, UNFPA, The World Bank and the United Nations Population Division.

11. Requejo JH, Bryce J, Barros AJ, Berman P, Bhutta Z, Chopra M, Daelmans B, De Francisco A, Lawn J, Maliqi B, Mason E. Countdown to 2015 and beyond: fulfilling the health agenda for women and children. The Lancet. 2015;385(9966):466-76

12. Wilmoth JR, Mizoguchi N, Oestergaard MZ, Say L, Mathers CD, ZureickBrown S, Inoue M, Chou D. A new method for deriving global estimates of maternal mortality. Statistics, Politics, and Policy. 2012;3(2).

13. Montagu D, Yamey G, Visconti A, Harding A, Yoong J. Where do poor women in developing countries give birth? A multi-country analysis of demographic and health survey data. PLoS One. 2011;6(2):e17155.

14. Central Statistical Agency/Ethiopia and ICF International. 2012. Ethiopia Demographic and Health Survey 2011. Addis Ababa, Ethiopia: Central Statistical Agency and ICF International.

15. Central Statistical Agency (Ethiopia), Ministry of Health (Ethiopia), World Bank. Ethiopia Mini Demographic and Health Survey 2014.

16. Chinkhumba J, De Allegri M, Muula AS, Robberstad B. Maternal and perinatal mortality by place of delivery in sub-Saharan Africa: a meta-analysis of population-based cohort studies. BMC Public Health. 2014;14(1):1014.

17. Hutton EK, Reitsma AH, Kaufman K. Outcomes Associated with Planned Home and Planned Hospital Births in Low-Risk Women Attended by Midwives in Ontario, Canada, 2003-2006: A Retrospective Cohort Study. Birth. 2009;36(3):180-9.

18. Simkhada B. Teijlingen ERv, Porter M, Simkhada P. Factors affecting the utilization of antenatal care in developing countries: a systematic review of the literature. J Adv Nurs. 2008;61(3):244-60.
19. Federal Democratic Republic of Ethiopia Population Census Commission. Summary and statistical report of the 2007 population and Housing census. Population size by age and sex Addis Ababa. 2008.

20. Desalegn E, Mekonnen A, Abeje G. Place of delivery after antenatal care: the case of Fogera district, Amhara region, North West, Ethiopia; 2013. J Gynecol Obstet. 2014;2(1):1-6.

21. Tarekegn SM, Lieberman LS, Giedraitis V. Determinants of maternal health service utilization in Ethiopia: analysis of the 2011 Ethiopian Demographic and Health Survey. BMC Pregnancy Childbirth. 2014;14(1):161.

22. Birmeta K, Dibaba Y, Woldeyohannes D. Determinants of maternal health care utilization in Holeta town, central Ethiopia. BMC Health Serv Res. 2013:13(1):256.

23. Teferra AS, Alemu FM, Woldeyohannes SM. Institutional delivery service utilization and associated factors among mothers who gave birth in the last 12 months in Sekela District, North West of Ethiopia: A community-based cross sectional study. BMC Pregnancy Childbirth. 2012;12(1):74.

24. Tsegay Y, Gebrehiwot T, Goicolea I, Edin K, Lemma H, Sebastian MS. Determinants of antenatal and delivery care utilization in Tigray region, Ethiopia: a cross-sectional study. Int J Equity Health. 2013;12:30

25. Amano A, Gebeyehu A, Birhanu Z. Institutional delivery service utilization in Munisa Woreda, South East Ethiopia: a community-based cross-sectional study. BMC Pregnancy Childbirth. 2012;12(1):105.

26. Bayu H, Adefris M, Amano A, Abuhay M. Pregnant women's preference and factors associated with institutional delivery service utilization in Debra Markos Town, North West Ethiopia: a community based follow up study. BMC Pregnancy Childbirth. 2015;15(1):1

27. Worku A, Jemal M, Gedefaw A. Institutional delivery service utilization in Woldia, Ethiopia. Sci J Public Health. 2013;1(1):18-23.

28. Tekelab T, Yadecha B, Melka AS. Antenatal care and women's decision making power as determinants of institutional delivery in rural area of Western Ethiopia. BMC Res Notes. 2015;8(1):1-8.

29. Abera M, Belachew T. Predictors of safe delivery service utilization in Arsi Zone, South-East Ethiopia. Ethiopian journal of health sciences. 2011;21(3).

30. Ayele G, Tilahune M, Merdikyos B, Animaw W, Taye W. Prevalence and associated factors of home delivery in Arbaminch Zuria district, southern Ethiopia: Community based cross sectional study. Science. 2015:3(1):6-9.

31. Van Eijk AM, Bles HM, Odhiambo F, Ayisi JG, Blokland IE, Rosen DH, et al Use of antenatal services and delivery care among women in rural western Kenya: a community-based survey. Reprod Health. 2006;3(1):2.

32. Mpembeni RN, Killewo JZ, Leshabari MT, Massawe SN, Jahn A, Mushi D, et al. Use pattern of maternal health services and determinants of skilled care during delivery in Southern Tanzania: implications for achievement of MDG5 targets. BMC Pregnancy Childbirth. 2007;7(1):29.

33. Mills S, Williams JE, Adjuik M, Hodgson A. Use of health professionals for delivery following the availability of free obstetric care in northern Ghana. Matern Child Health J. 2008;12(4):509-18.

34. Nduka I, Nduka E. Determinants of noninstitutional deliveries in an urban community in Nigeria. J Med Investig Pract. 2014;9(3):102.

35. Wagle RR, Sabroe S, Nielsen BB. Socioeconomic and physical distance to the maternity hospital as predictors for place of delivery: an observation study from Nepal. BMC Pregnancy Childbirth. 2004;4(1):8.

36. Abeje G, Azage M, Setegn T. Factors associated with Institutional delivery service utilization among mothers in Bahir Dar City administration, Amhara region: a community-based cross sectional study. Reprod Health. 2014;11(1):22.

37. Ekele BA, Tunau KA. Place of delivery among women who had antenatal care in a teaching hospital. Acta Obstet Gynecol Scand. 2007;86(5):627-30.

38. Faye A, Faye M, Bâ I, Ndiaye P, Tal-Dia A. Factors determining the place of delivery in women who attended at least one antenatal consultation in a health facility (Senegal). Rev Epidemiol Sante Publique. 2010;58(5):323-9.

39. Karkee R, Binns CW, Lee AH. Determinants of facility delivery after implementation of safer mother program in Nepal: a prospective cohort study. BMC Pregnancy Childbirth. 2013;13(1):193.

40. Mengesha ZB, Biks GA, Ayele TA, Tessema GA, Koye DN. Determinants of skilled attendance for delivery in Northwest Ethiopia: a community based nested case-control study. BMC Public Health. 2013;13(1):130.

41. Feyissa TR, Genemo GA. Determinants of Institutional Delivery among Childbearing Age Women in Western Ethiopia, 2013: Unmatched Case Control Study. PLoS One. 2014:9(5):e97194.

42. Zegeye K, Gebeyehu A, Melese T. The Role of Geographical Access in the Utilization of Institutional Delivery Service in Rural Jimma Horro District, Southwest Ethiopia. Prim Health Care. 2014;4(150) doi:10.4172/2167-1079.1000150. 